Fecha de recepción: marzo 2015 Fecha de aceptación: junio 2015 Versión final: marzo 2016

\section{Interferencias. Notas sobre el taller como territorio, la regla como posibilidad, la obra como médium}

Viviana Suarez *

\begin{abstract}
Resumen: Quizás sea un tópico recurrente entre quienes nos dedicamos a la enseñanza el asumir que la relación entre docente y estudiantes -así en plural, como entidad colectivase ha problematizado en los últimos tiempos, y señalar como razón principal los cambios producidos en los sistemas referenciales y comunicacionales a partir de la propagación y masificación del uso de las tecnologías digitales; el habitar nuevos entornos que requieren ser continuamente interpretados para poder ser justamente habitados.

Este ensayo se propone reflexionar sobre la práctica pedagógica en talleres relacionados con la producción de obra e imágenes artísticas y su relación con el saber que la sustenta, cuestiones ubicadas entre los polos de la praxis y el episteme que reclaman ser pensados en su articulación; el juego de las subjetividades que entran en tensión durante el proceso de enseñanza-aprendizaje y el de la función de obra en tanto objeto de producción intermedio entre la subjetividad y el mundo.
\end{abstract}

Palabras clave: estética - ethos - experiencia - pedagogo - profesor - médium - regla - territorio.

[Resúmenes en inglés y portugués en la página 226]

${ }^{*}$ Arquitecta (UBA). Docente en la Diplomatura en Investigación y Conservación fotográfica documental de la UBA y del Departamento de Diseño y Comunicación de la Universidad de Palermo.

\title{
Introducción
}

Escribo este ensayo subrepticiamente como un ejercicio de recopilación: notas sobre mi práctica pedagógica en disciplinas que involucran la creación de obras en los nuevos regímenes de imágenes; la subjetividad creativa y el papel del autor; y, por sobre todo, el ejercicio de la docencia en un estado de mundo lábil, impreciso, problemático por sobreabundancia de información y desarticulación entre experiencias individuales y colectivas, relacionadas por briznas. Estado de mundo todavía actual, al que el antropólogo francés Marc Augé define como sobre-modernidad ${ }^{1}$ y en el cual nos involucramos en el proceso de enseñanza-aprendizaje desde ciertas experiencias intersubjetivas, espacio-temporales y de 
producción de obra preñadas de cierta normalidad que habremos de desmontar creando para ello una pedagogía de la interferencia.

Notas sobre ciertas impresiones personales, subjetivas, decantadas de mi experiencia en talleres de arte, de fotografía, de diseño y de teoría, pensadas como traspaso de prácticas, tácticas, modelos desde un campo -el arte- a otro -el institucional-creadores ambos de expectativas, supuestos, metodologías y conceptos sobre la realidad divergentes; así como divergen también sus programas en la transmisión de saberes, la relación entre los sujetos implicados y la producción de objetos, materiales o conceptuales. Traspaso que implica una fricción, en última instancia, entre los campos del hacer y el saber, entre praxis y episteme; ejercicio de una interferencia en la fluidez interdisciplinaria. Porque de lo que se trata es de que, en definitiva, un campo -con sus interrogantes, sus búsquedas, sus incertezas- desbarate al otro, lo cuestione, lo suspenda y a la vez lo movilice. Análogo objetivo al que declara Marcel Duchamp al explicar a Jean Susquet en una carta del 25 de diciembre de 1949 sus intenciones sobre La Novia puesta al desnudo por sus solteros, mismo o Gran Vidrio:

A fin de cuentas el vidrio no está hecho para que lo miren (con ojos estéticos): debía ir acompañado de un texto de "literatura" lo más amorfo posible que jamás cobró forma, y ambos elementos, vidrio para la vista y texto para el oído y el entendimiento, debían completarse y sobre todo impedirse mutuamente la posibilidad de cobrar una forma estético plástica o literaria. (Duchamp, 1978, p. 31).

Relación entre incertezas artísticas y precisión del campo disciplinario: pienso este impedimento mutuo de cobrar forma como una estrategia o método: de búsqueda, de ensayo, de impedir caer en la repetición de lo sabido, de lo agradable. Notas sobre la experiencia de la pedagogía que se obstine en cuestionar lo dado, las regularidades, los presupuestos, las normalidades aceptadas, aún la del lugar de quienes ofrecemos el material a ser consumido como conocimiento. Y de la idea misma de que sea ése un material a ser consumido. Pero, antes que todo, notas sobre la etimología: del pedagogo, del maestro, del profesor, del docente. Nota reveladora en términos del ejercicio concreto de la enseñanza-aprendizaje en cuanto herramienta que define una topología de los actores-sujetos y de sus campos simbólicos asociados. Reveladora del juego de posiciones que se despliega básicamente en el terreno del imaginario, en el que se involucran espacios, tiempos, cuerpos que dan y reciben, construcción de saberes y objetos. Por lo tanto: primera nota de interferencia .

\section{El juego de las posiciones}

Antes que nada comencemos por dibujar las redes imbricadas de la etimología. Docente deriva de la palabra latina docera que a su vez se forma con la raíz indoeuropea dek: "pensamiento, aceptación". Raíz que comparte con doctrina, doctor, documento y dócil formando así una familia de palabras de la que sin embargo queda fuera educación, ya que ésta deriva en cambio de la -también indoeuropea- $d u k$ : guiar. Y así, mientras educar se imbrica en su origen con conducir y con la conducta como manera de comportarse, 
docente se centra antes que nada en la relación en sí entre la enseñanza y el aprendizaje con preeminencia del pensamiento e, implícitamente, de la docilidad.

Pedagogo es literalmente "quien lleva de la mano al niño". Raíces griegas - ago "yo conduzco" al paidon "niño" - que figurativizan la actividad de la enseñanza-aprendizaje como el ejercicio de caminar juntos siendo uno guía del otro. Al igual que en educar: acompañamiento, sostén y orientación. Muy distinta es la posición del maestro, cuya raíz se encuentra en el Magis Stare latino, literalmente "el que está parado más alto". Magister: el que llega al mayor grado en su área y por su experiencia se encuentra por arriba de los Ministiri (minus) subordinados. En Roma se llamaba Magistiri a los esclavos griegos libertos que enseñaban en casas de los patricios. El maestro de escuela era en cambio el Literator quien se ocupaba principalmente de la enseñanza de las letras (liter).

A su vez, profesor deriva de la también latina profiteri: "el que habla delante del público". Su campo semántico deriva de fateri "confesar, admitir" y, por lo tanto, comparte raíces con profesar y confesar, familia de palabras que hacen girar su significación predominantemente en torno al discurso y el decir verdad.

Si desplegamos entonces estas posiciones en una matriz que diseñe una topología intersubjetiva entre los dos actores involucrados directamente en el proceso, advertiremos que el imaginario de la docencia articula diferentes figuras que activan relaciones y posiciones de poder relativas desde las que pueden jugarse distintos grados de libertad de la actividad. Juegos de libertad con los que podrían movilizarse las tácticas en el aula-taller como territorio, esto es, en un espacio/tiempo concretos donde desplegar prácticas entre actores concretos que pongan en juego condiciones específicas de ejercicios de libertad. Pensemos sobre cuáles pueden ser estas estrategias que nos permitan pasar de la posición del profesor, guardián de una distancia necesaria y constituyente frente al otro para quien habla, esa audiencia que escucha, mira y toma nota desde una corporalidad fijada por esa relación de expectación y la vez de exhibición de la verdad (recordemos que el profesor profesa y confiesa en público), a otra vinculada con la transferencia de una experiencia, como en el caso del maestro, figura que carga su autoridad por su maestría amasada de experiencia acumulada en el ejercicio, el ensayo, el error, el legado, la historia. El maestro, figura derivada de la praxis, el taller, el oficio evoca a la sabiduría como contraparte dialógica del profesor, ligado al episteme, la institución teórica y el conocimiento universal.

Dos modelos que, en la práctica del aula-taller actúan sucesivamente creando un ritmo alternante entre momentos de praxis y momentos de episteme. Volveremos sobre estos temas al referirnos a la cuestión de la razonabilidad ética y estética de la pedagogía.

\section{Del aula al taller. La cuestión del territorio y la regla}

"Para apartar el todo hecho en serie al todo hallado. El apartamiento es una operación". (Duchamp, 1978, p. 37). 


\section{Primera cuestión: oposiciones de territorios}

Figuremos primero la escena o mejor el campo en sentido gestáltico en el que transcurre este proceso espacial y temporalmente limitado, pausado, reglado del trasvasamiento del conocimiento. Y tratemos de llenar este espacio-tiempo pensándolo como territorio que se ocupa y desde el cual se despliegan ciertas tácticas que cubren relaciones interpersonales, esto es, que involucran subjetividades corporalizadas.

Consideremos al aula-taller como locus, como territorio orientado espacial y temporalmente, recorrido por tensiones que participan activamente en la transmisión del saber. El territorio áulico es, además, un locus fuertemente ocupado lo que implica una ubicación precisa de los actores en el espacio estableciendo preferencias -de interés o deseo-, pertenencias -grupos afectivos, intelectuales, prácticos-, posiciones -según mayor o menor participación- todo lo cual da como resultado un juego de energías que se distribuyen anisótropamente en tiempos rapsódicos, discontinuos, involucrando desplazamientos de cuerpos, toma de posiciones, cambios de referencias, sectorizaciones, particiones. En las organizaciones espaciales clásicas establecidas por la concepción pedagógica decimonónica para la enseñanza popular masiva que todavía persisten, el espacio aula se experimenta como una topología anisótropa. Límites precisos para cada espacio-aula, con una relación adentro-afuera muy enmarcada que propicia prácticas pedagógicas en las que predomina la concentración en la actividad desde el encierro y el paréntesis temporal (de tal hora a tal hora); e interiormente una cisura demarcatoria entre espacios adelante-atrás a partir del despliegue de una serie de dispositivos (en el sentido foulcaultiano): escritorio, pizarras, pantallas de proyección destinados al profesor versus asientos y superficies de trabajo (muy a menudo) rigurosamente ordenados por filas e hileras para los estudiantes. El espacio organizado de este modo privilegia la relación audiovisual y asimétrica profesor-estudiante, e implica el desarrollo de un flujo unidireccional desde el habla de un sujeto único (con la gestualidad y la proxemia que involucra) a una mirada-escucha de muchos ${ }^{2}$. Al mismo tiempo establece en el imaginario una relación fija entre agente activo- receptores pasivos, práctica que reduce la presencia corporal a un juego de escuchas y miradas sostenidas que se constituyen en torno a la figura del Profesor, que viene a ocupar en el imaginario el lugar del veredictor ${ }^{3}$ en este entorno configurado por dispositivos que funcionan fijando lugares establecidos según la fenomenología del ojo-oído. Herman Parret (1984) lo especifica de este modo: "El docente desarrolla un programa platónico. Es mono-lógico porque representa la Verdad. Ejerce una transferencia de la Verdad sin reciprocidad".

$\mathrm{Si}$, en cambio, organizáramos este territorio espacio-temporalmente desde el modelo del pedagogo, el que camina junto al paidon, se nos presentarían en lugar de sujetos sujetados a la visión-escucha, cuerpos en movimiento marcando posiciones con un grado mayor de presencia y exposición tanto gestual como fonemática; un estar entre otros que implica mayor ubicuidad y horizontalidad a la vez, desarticulando la asimetría espacial que toma como eje a quien profiere el discurso de la verdad. El juego de presencias del veredictor frente a su audiencia está perfectamente escenificado en la disposición de auditorio, modelo espacial que rearticula el eje delante-atrás -que en el aula adopta la forma de espacio proescénico para el profesor-como posición alta-posición baja. A esto puede contraponérsele la disposición en archipiélagos propia del aula-taller, en la que el territo- 
rio es armado por la adición de mesas-trabajo dispuestas en figuras que evocan simetrías vagamente axiales; ordenamiento que desactiva el carácter eminentemente exhibitivo de la figura Profesor al mismo tiempo que produce una integración de la periferia como espacio articulado. A la vez, el estar junto del pedagogo inaugura ritmos temporales alternativos como la simultaneidad y la ruptura del unísono -el compás que establece la voz del Profesor- por la multivocidad -muchos al mismo tiempo a diferentes velocidades, ayudando a construir una percepción de actividades plurales y comunitarias. El tiempo del taller es un tiempo tensivo, constituido por momentos de espera y disponibilidad que suceden a otros de actividad generando una conciencia acentuada de las ritualizaciones de comienzos-finales, ciclos, duratividades; más cercano a la percepción de un tiempo orientado que a la progresión meramente cronológica del "tiempo que pasa".

Esta reconfiguración del espacio-tiempo en forma de organización territorial busca generar una interferencia con el dispositivo del aula-clase tradicional, más diferenciado y jerarquizado, concebido según el criterio de disciplinamiento y vigilancia ejercido por Uno sobre Muchos tal como lo señalara Foulcault ${ }^{4}$, al proponer mayor dispersión de actividades y proximidad del maestro como guía, que se desplaza y particiona su tiempo: del "a todos" simultáneo de la exposición al "a cada uno" sucesivo del seguimiento en la actividad. El modelo del pedagogo nos propone de esta manera crear un imaginario en el que la figura de quien posee e imparte el conocimiento adquiera mayor flexibilidad y accesibilidad a la vez que aumenta el contacto entre cuerpos utilizando como mediador el ejercicio de una práctica concreta.

Podríamos sintetizar esta primera interferencia con dos figuras modélicas que se "impiden mutuamente" tal como desea Duchamp: la arché del dispositivo clásico, caracterizada por juegos de posiciones de uno ante muchos, la comunicabilidad audiovisual de un hacer saber centrado en el episteme, el flujo unívoco y lo exhibitivo. Como contrapartida, la anarché ligada al dispositivo artístico, con posiciones junto, momentos lagunares, acentuación de la praxis, el saber hacer y la corporalidad. Tal como nos hace notar Michel Foulcault (1990) "todos pensamos y actuamos al mismo tiempo": la interferencia busca frotar saber contra actuar para crear actividades reflexivas/reflexiones activas, alternando ambos modelos estratégicamente durante el curso.

Sin embargo es fundamental tener en cuenta que, en cualquiera de los dos dispositivos, el otro siempre es un sujeto colectivo, lo que nos lleva a pensar cómo organizar este interactuar de los sujetos-cuerpos configurando la regla.

\section{Segunda cuestión: la regla y los otros}

Consideremos el problema del conocimiento. El saber común lo imagina -y define-como un bien de intercambio intelectual, dando por sentado que se trata predominantemente de una relación entre inteligencias. Jacques Ranciére ${ }^{5}$ (2010) ha analizado este tema dentro de sus consideraciones sobre la recepción de las obras de arte, ya que este caso en particular hace evidente otros tipos de relaciones sujeto-objeto-sujeto ligadas a la percepción, la emoción y el sentimiento más que a la apreciación exclusivamente intelectual. Ranciére encuentra que el modo de relación intersubjetiva clásica docente-alumno supone conce- 
bir la desigualdad intrínseca de las inteligencias, cuyo paradigma podría centrarse en la figura del Profesor que describimos anteriormente en la cual quien posee el conocimiento lo transmite (vía disertación) a quienes lo ignoran, manteniendo continuamente esta distancia insalvable, pues el profesor siempre conocerá algo más que el alumno, personaje caracterizado predominantemente en función de su ignorancia, abriendo continuamente una puerta al futuro "algo más todavía que conocer" como motor de deseo. El problema, básicamente, es que este modelo disocia inteligencias de cuerpos mostrando, además, su ligazón de origen con la concepción cartesiana de lo humano, ente binario compuesto de manera disjunta por alma y materia corporal. También es de notar que esta relación conflictual entre alguien que conoce y otros que ignoran, conduce a una visión polémica de las relaciones intersubjetivas, ya que la matté -aquello que está en disputa- es precisamente el deseo de hacer desaparecer esta diferencia entre conocimiento e ignorancia; deseo de llegar a ocupar el lugar del otro, el Maestro, y colocarse a su vez imaginariamente en posición supina respecto de los otros (recordemos que etimológicamente Magis Stare es el que mira desde una posición más elevada). Este imaginario cambia abruptamente si nos colocamos, en cambio, en una posición inter-corporal tal como propone Emanuel Levinas, considerando entonces como condición esencial del otro la de no ser reductible a lo mismo ${ }^{6}$. Conservar la diferencia, hacer entrar en el juego el cuerpo del otro como límite, es producir una interferencia en el saber común sobre lo esperable en el proceso de adquisición del conocimiento. Desgajando nuevamente otra consideración duchampiana podríamos decir que, al igual que en el Gran Vidrio la Novia con los Solteros, de lo que se trata es de hacer salir al otro de su goce solipsista, o en palabras del propio Duchamp: "Novia: operación alterna. Cortocircuito si hace falta" (1978, p. 52). Esta nueva interferencia sería entonces la productora de una refocalización del objetivo de la enseñanza: no como la mera adquisición de un expertise donde el otro ocuparía en un futuro el lugar del maestro, sino como la conservación de la diferencia radical del otro, es decir el ethos que implica la enseñanza-aprendizaje. Por una parte, aparece aquí la figura del autor como artista en su rol de creador en la diferencia ${ }^{7}$. Y por otra la del ethos como cuidado de sí tal como lo define Michel Foucault:

Sin duda uno no puede cuidar de sí sin conocer. El cuidado de sí es el conocimiento de sí -en un sentido socrático-platónico- pero es también el conocimiento de un cierto número de reglas de conducta o de principios que son a la vez verdades y prescripciones. El cuidado de sí supone hacer acopio de estas verdades y es así como se ven ligadas la ética y el juego de la verdad. (1984, p. 101)

Por otra parte, en este párrafo se hace evidente la red de conexiones que unen al sujeto-encomunidad, la verdad y la regla, tríada sobre la que la pedagogía actúa sin cesar, generando varios tipos de enlaces e intercambios.

Tomemos por caso la regla en su relación con el otro y analicémosla desde varias perspectivas.

Por un lado la regla como $\mathrm{ley}^{8}$, gran problema kafkiano ${ }^{9}$ del sujeto sujetado al Otro inabarcable e inimaginable, que presenta varios aspectos: 
1. La naturaleza de la ley: orden natural o convención social. En ambos casos la ley se presenta como limitativa, excluyente y prohibitiva: transgredir la ley natural significa ingresar al campo de la anormalidad mientras que transgredir la ley social es entrar en el campo de lo punitivo y del castigo ${ }^{10}$.

2. Lo que nos lleva a la cuestión de la sanción de la ley (Dios o quien detenta la autoridad para promulgarla). Voz de autoridad, ocupa el rol de enunciador-performador, quien hace diciendo, estableciendo así los límites entre legal e ilegal ${ }^{11}$, problemas ligados tanto con la Verdad como con el Decir Verdad. Recordemos la familia etimológica que une profesar y confesar, figuras que abren el campo imaginario de quien habla comprometido con la Verdad exhibida -y contraída- ante muchos.

3. La escritura de la ley: por último, visibilización de la sanción en un corpus escrito, el reglamento, que une la palabra de la ley fijada por la escritura al principio de obediencia a la ley.

Si a esta noción restrictiva de la regla como ley-deber hacer y sobre todo deber decir- le contraponemos la más lúdica de la regla como regularidad, red y práctica de posibilidades, podremos pensar procesos que involucren relaciones intersubjetivas menos coercitivas, ajustadas en mayor medida al ejercicio ético de la libertad como cuidado de sí tanto como a distintos grados de libertad respecto de las posiciones de poder y el ejercicio de la autoridad. La regla se presenta entonces como ocurrencia reiterada, como regularidad, más cercana a la idea de hábito y convención que a la Verdad. Al pensar sobre qué tipo de reglas podría regular el vivir juntos en comunidades muy pequeñas, Roland Barthes (2003, p.71) despliega la etimología de esta palabra. Su origen es el vocablo griego orego: extender en línea recta, trazar hacia adelante una línea recta, vinculado a su vez al instrumento que se utiliza para medir. Lo regulado (medible) se relaciona con el control vía sistematización antes que prohibición y quien regula (el rex) es quien conduce, lo que nos permite vincular de esta manera regla y práctica del pedagogo como conductor, como guía. Por otra parte, el rex regula un territorio, demarcando límites y ejes, lo propio de lo ajeno, lo organizado de lo periférico, lo común de lo anonímico. Marca el tiempo y el entorno de lo cotidiano: "La regla, acto ético (se puede decir incluso, en ciertos casos, místico) cuyo fin, repito, es darle transparencia a la vida, a la cotidianeidad". (Barthes, 2003, p. 174)

La regla pensada de esta manera, como acto individual puesto en comunidad -dice Parret (1984) "convivir es organizar las libertades individuales"- y como marca de lugar y de ritmo temporal implícito en las tareas cotidianas, carga a la tríada espacio-tiempo-subjetividad de corporalidad, alejándola del tiempo-espacio vacío característico de la sobremodernidad $^{12}$.

Por otra parte, la idea de regla en nuestra contemporaneidad pareciera estar fuertemente ligada a lo lúdico, y por lo tanto al desarrollo de tácticas y estrategias a partir de un programa narratológico en busca de un objetivo ${ }^{13}$, lo que involucra el despliegue de cierto orden lógico motivado en lograr el objeto de deseo ${ }^{14}$, como lo muestra -nuevamente- el Gran Vidrio duchampiano en la figura del magneto-deseo que la Novia agita sobre los Solteros, poniendo en funcionamiento su máquina.

Al contrario de la ley kafkiana vinculada con la máquina mecánica y el funcionario que no puede verse por fuera del mecanismo del aparato - mecanismo transracional por otra par- 
te- la regla procedimental y programática, sistematizadora encuentra su campo asociativo en la idea del artista como creador de programas metodológicos, técnicos, formales, temáticos, estilísticos, es decir, estéticos, que abren un campo de posibilidades de realización de ciertas formas-contenidos al mismo tiempo que restringe otros. Idea vinculada a la definición de grados de libertad de un sistema dado por la Física. Casi todas las vanguardias modernistas produjeron sus Manifiestos ${ }^{15}$ : instrumentos para la elaboración de sistemasguías de producción de obras pensadas como campo de exploración del funcionamiento de reglas en una estructura formal o temática dada. El Manifiesto, por otra parte, tiene un enunciador explícito, casi siempre colectivo, que lo da a conocer, es decir, lo hace público; es programático y al mismo tiempo fundamentado en cierta toma de posición respecto de un estado de cosas (del mundo, del arte, del sujeto).

Si contraponemos la idea de la Ley como regla limitativa, coercitiva y excluyente, cuyo enunciador siempre es absoluto y universal a la idea de Regla como regularidad, en la que se hace evidente su grado de convención (acuerdos), su grado de pertinencia (alcance), y por lo tanto su relativismo y multiplicidad, podremos confrontar la primera con esta segunda vía de forma de provocar un cortocircuito que encauce, desde el ethos de la pedagogía, la tensión siempre conflictiva entre actos de libertad y observación de la normatividad.

\section{Del autor a la obra. El objeto mediúmnico}

"Lo posible es únicamente un mordiente físico (género vitriolo) que quema cualquier estética". (Duchamp, 1978, p. 88)

Llegamos así a la tercera interferencia que introduce la propia obra llamada de arte como reflexión de un estado de mundo; obra que actúa como médium entre una subjetividad corporalizada y un territorio exterior. Existe una fuerte carga de utopía en toda obra que roce de alguna manera el campo del arte dada precisamente por el acto de creación. Como señalara Duchamp, cualquier acto de creación artística tiene como consecuencia la creación de un objeto que no es requerido por nadie, que no satisface ninguna necesidad vital inmediata y que es ofrecido por el artista para expresar su visión sobre un estado de mundo, visión que nadie ha pedido conocer a priori.

Precisamente Alfredo Jaar, en una entrevista de 2008 para la televisión chilena, reflexiona sobre este rol del artista en nuestro mundo sobre-moderno contemporáneo y su objetivo de llegar -a través de la creación, producción y exhibición de obras- desde la subjetividad al mundo:

Es un salto difícil. Muy difícil. Es un acto de fe, en el fondo. No sólo de parte del artista sino que también demanda un acto de fe por parte del espectador. Porque vivimos en tiempos difíciles. Y nos enfrentamos a una realidad difícil. Que siempre me pareció imposible de representar. Y siempre he pensado que en vez de representar esta realidad nosotros [los artistas] creamos una nueva realidad. Entonces, este salto al mundo, este mundo al que incorporamos nuestras obras, también es una nueva realidad. Entonces hay ahí un vacío, un vacío muy grande, entre ese mundo real -si lo 
podemos llamar así- y este mundo inventado por el artista. Y este foso es el que a mí me interesa explorar. Este vacío. Y muchas veces uno se pierde en el salto y no aterriza en ninguna parte. Y ahí está la dificultad. (2008)

Jaar pone de relieve la importancia del tránsito o pasaje entre dos estados o mundos: el onmipresente real y el utópico posible; mundos disociados para los cuales la obra actúa como paso o puente, mordiente físico al decir de Duchamp "que quema cualquier estética $^{16 ”}$, es decir cualquier conformidad con lo dado. Y asimismo Ranciére (2010) señala que la función principal de la obra de arte contemporánea es descolocar el orden preestablecido, $u$ orden policíaco de la mirada ${ }^{17}$. Pero, al mismo tiempo, Jaar hace notar que el final de este proceso es incierto. Porque la obra vinculada al campo del arte se caracteriza precisamente por vehiculizar su contenido tanto en lo que exhibe como en lo in-expresado, en aquello que emerge desde lo no dicho en la superficie de lo evidente. Sin embargo, esta ambigüedad no es algo que esté deliberadamente oculto sino lo que el propio mensaje no puede develar explícitamente. Esta zona opaca presente en toda obra fue el lema convocante de la 30 Bienal de San Pablo: La inminencia de las poéticas. Su curador Luis Pérez Orama (2011) lo explica de este modo:

Las poéticas son un repertorio limitado de enunciados o de actos de enunciación dentro de un campo artístico (una práctica), una tradición o un espacio histórico-cultural. En este sentido, las poéticas pueden tener mayor o menor relevancia colectiva o temporal, mayor o menor pertinencia y mayor o menor eficacia. La temporalidad de las poéticas es diferente de la temporalidad de la moda, así como de la temporalidad de la historia: las poéticas son actos y como tales, siempre se tornan presentes; están al borde de ser materializados; son imprevisibles; como 'la palabra en la punta de la lengua' estos actos discursivos -que también incluyen las modalidades de suspensión y de interrupción del discurso- se nutren de densidades discursivas anteriores, de una memoria orgánica de actos enunciativos o expresivos que los preceden y los alimentan y que estos, cada vez, alteran, deforman, asimilan -en su advenimiento impensable.

Desde el punto de vista del autor, la poética podría ser entendida como el rodeo que la subjetividad da a través de la obra, movimiento abarcativo, envolvente que obliga a desplegarse. Este desenvolvimiento está fuertemente vinculado con la razón estética, cuyos juicios -impalpables- no dependen de la adecuación conceptual de la razón teórica, centrada en la verdad demostrable, ni con la racionalidad argumentativa de la esfera de lo práctico vinculada como vimos a lo ético y la felicidad, sino con la belleza y lo contemplativo. Al respecto Herman Parret señala que la razón estética, siguiendo a Kant, está ligada con la thymia, sentimiento universal y profundo, trans-lógico y sinestésico:

Los estetas son entusiastas y recognoscentes, lo cual quiere decir que reconocen su participación en una universalidad comunitaria donde la belleza puede y debe ser juzgada igualmente por todos. (1984, p. 155) 
Lo contemplativo introduce la esfera del contacto dentro de la pura visibilidad, Y es así que, a través de la obra, podremos deplegar una tactología de la pedagogía, obra que se aparece a la vez como mediadora de la experiencia y objeto incierto.

\section{Breve epílogo}

Podríamos sintetizar las intenciones de estas notas de la siguiente manera: intenciones de trasvasar prácticas y saberes del campo del arte al pedagógico, generando -desde esta articulación- interferencias que actúen como impedimentos para aplicar mecánicamente (el todo hecho en serie) conductas, ritos y costumbres preadquiridos (el goce estético o literario) sin problematizarlos. Y centrar el objeto a crear como escollo o resistencia (magnetodeseo) que promueva la predisposición al azar (el todo hallado) y la obra como mordiente físico (género vitriolo) que obstruya por sí misma toda predisposición a la repetición.

\section{Notas}

1. Augé M. (2003) Lo demasiado lleno y lo vacío. El tiempo en ruinas. Disponible en: http://bibliotecaignoria.blogspot.com/\#ixzz2Jfz52cEH. Consultado el 20 noviembre 2012.

2. Esta fenomenología del espacio que se estructura en torno a la audiovisión es tratada en el capítulo VIII Tocar en Parret H. (1984) De la semiótica a la estética. Buenos Aires: Edicial (pp. 145-164).

3. Existe un magnífico dibujo en el que Otto Dix se autorretrata como veredictor en su rol de profesor de pintura, la mirada fija y severa tras unos anteojos redondos, el cuerpo rígido, la mano izquierda en alto, la derecha sobre el estómago y el guardapolvo abotonado. Todo en su figura conduce a la imagen de un juez dictando sentencia. Ver Gómez Molina, J.J. (1995) Las lecciones del dibujo. Madrid: Cátedra. p. 39.

4. Ver Foulcault M. entre otros textos Vigilar y castigar, nacimiento de la prisión; Tecnologías del yo y Los anormales.

5. Ranciere J. (2010) El espectador emancipado. Buenos Aires: Manantial.

6. Beavers, A. (1995) Introducing Levinas to Undergraduate Philosophers. Disponible en: http//faculty.evanville.edu/tbz/PDFS/undergradPhil.pdf. Consultado el: 2 de enero de 2013. 7. Esta figura del autor como mónada de la diferencia es analizada por Deleuze G. (2002) Proust y los signos. Madrid: Editora Nacional.

8. Ver Foucault M. (2000) Los anormales. Buenos Aires: Fondo de Cultura Económica.

9. Tanto en El proceso como en El Castillo, F. Kafka desarrolla esta noción de sujeto sujetado a la ley como Otro absoluto, inaccesible e incluso inimaginable, y la imposibilidad de penetrar los círculos interminables de funcionarios y servidores que rodean al que sanciona y sostiene la Ley. V. Flusser toma esta figura para desarrollar su concepción del hombre sujetado de la modernidad por su función de funcionario.

10. Sobre la regla y la ley ver Barthes R. (2003) Cómo vivir juntos. Buenos Aires: Siglo XXI, p. 174. 
11. Nuevamente, ver en op. cit. Foucault M. (2000) el rol que va ocupar en los juicios, paulatina y crecientemente, el psiquiatra como veredictor, al introducir el orden natural (normal/anormal) como principio discriminador dentro de la ley social (legal/ilegal).

12. Idem Augé M. (2003).

13. Obviamente nos referimos a una generación criada mayoritariamente en la práctica de juegos virtuales, estructurados predominantemente según programas semio-narrativos, la subjetivización en la adopción de un rol, el autoaprendizaje por iteración y la observancia de reglas explícitadas en el propio territorio lúdico.

14. Nos referimos al programa narratológico clásico expuesto por los análisis estructuralistas del relato como por ejemplo el de Greimas y Cortés.

15. En las vanguardias europeas y rusas de pre y entreguerras el Manifiesto Surrealista, el Neoplasticista, el Futurista, el Constructivista, los procedimientos del Cubismo, los fundamentos del Teatro de la Crueldad de Antonin Artaud, o Bertold Brecht; o en Sudamérica el del Arte Concreto-Invención, las búsquedas de Gyula Kósice o el Manifiesto Antropofágico de Oswald de Andrade como ilustración de unos pocos entre muchos ejemplos. 16. Para Duchamp, aquí el concepto de estética adquiere el sentido connotado de cierta complacencia en lo agradable, lo reiterativo, la comodidad de factura, cierta facilidad de creación por recurrencia a un "estilo". Por eso los ready-mades fueron concebidos desde la indiferencia estética.

17. Ver op. cit. Ranciére J. (2010) El espectador emancipado.

\section{Referencias bibliográficas}

Augé M. (2003) Lo demasiado lleno y lo vacío. El tiempo en ruinas. Disponible en: http:// bibliotecaignoria.blogspot.com/\#ixzz2Jfz52cEH. Consultado el 20 noviembre 2012.

Barthes, R. (2002) Cómo vivir juntos. Notas de cursos y seminarios en el Collége de France 1976/1977. Buenos Aires: Siglo Veintiuno.

Duchamp, M. (1978) Escritos. Barcelona: Gustavo Gili.

Foulcault M. (1984) La ética del cuidado de uno mismo como práctica de la libertad. Disponible en: http://www.topologik.net/Michel_Foucault.htm. Consultado el 24 de enero 2013.

Foulcault M. (1990) Tecnologías del yo. Barcelona: Paidós.

Foulcault M. (2000) Los anormales. Curso en el Collége de France. Buenos Aires: Fondo de Cultura Económica.

Jaar A. (2008) Una Belleza Nueva [Programa televisivo] Disponible en: Parte 1: http:// www.youtube.com/watch?v=C4O7uQ54hW8. Parte 2: http://www.youtube.com/ watch? $\mathrm{v}=\mathrm{nQkGbVCpb30}$. Consultado el 27 de febrero 2013.

Parret H. (1984) De la semiótica a la estética. Enunciación, sensación, pasiones. Buenos Aires: Edicial.

Ranciére J. (2010) El espectador emancipado. Buenos Aires: Manatial.

30 Bienal de San Pablo (2012) Informaciones de la Bienal de San Pablo. Disponible en : http://universes-in-universe.org/esp/bien/bienal_san_pablo/2012. Consultado el $30 \mathrm{de}$ noviembre del 2012. 


\section{Bibliografía}

Deleuze G. (2002) Proust y los signos. Madrid Editora Nacional.

Foulcault M. (2005) Las redes de poder. Ferrer C (comp.) El lenguaje libertario. Antología del pensamiento anarquista contemporáneo. La Plata: Terramar.

Flusser V. (2007) Del funcionario. En Kozak C. Arte y técnica. Vilém Flusser sobre arte, técnica y funcionarios. Artefacto. Pensamientos sobre la técnica. 6. Disponible en: http:// www.revista-artefacto.com-ar. Consultado el 16 de agosto 2012.

Parret H. (1990) Las pasiones. Buenos Aires: Edicial.

Summary: Perhaps it is a recurring topic among teachers the assumption that the relationship between teacher and students has been troubled in recent times. Also it is noted that the main reason for those changes in the reference and communications systems are the propagation and spread of the use of digital technologies; inhabiting new environments that require a continuous interpretation to be just inhabited.

This essay proposes to reflect on teaching practice in workshops related to artistic images production and their relationship to knowledge; issues located between episteme and praxis that claim to be thinked in its articulation; the play of subjectivities that are in tension during the process of teaching and learning and the role of work as an object of intermediate production between subjectivity and the world.

Key words: aesthetics - ethos -experience - educator - professor - medium - rule - territory.

Resumo: Os professores assumem que a relação entre eles e os estudantes se problematizou nos últimos tempos devido às mudanças produzidas nos sistemas referenciais e de comunicação a partir da propagação e massificação do uso das tecnologias digitais. Este trabalho propõe refletir sobre a prática pedagógica em oficinas em relação à produção de obra e imagens artísticas e sua relação com o saber que a sustenta, questões localizadas entre os pólos da práxis e o episteme que reclamam ser pensados em sua articulação; o jogo das subjetividades que entram em tensão durante o processo de ensino-aprendizagem e aquele da função de obra em tanto objeto de produção intermédio entre a subjetividade e o mundo.

Palavras chave: estética - ethos - experiência - pedagogo - professor - médium - regra território. 